\title{
EFFECT OF COAL SMOKE POLLUTION ON THE BIOMASS AND CHLOROPHYLL PIGMENTS OF Brassica juncea
}

\author{
Mohammad Saquib \\ Department of Biological Sciences \\ Kebbi State University of Science and Technology \\ Aliero, Kebbi State, Nigeria
}

\begin{abstract}
The effect of coal smoke pollution on the biomass and chlorophyll pigments of Brassica juncea were studied at $0.5,2,4,6$ and $20 \mathrm{~km}$ distance leeward from a thermal power plant complex. The root, shoot and total biomass and chlorophyll a, chlorophyll $\mathrm{b}$ and total chlorophyll were significantly reduced up to a distance of $4 \mathrm{~km}$ from the source of pollution. The data indicates that the degree of response increased with decreasing distance from the source of pollution in comparison to the reference site 'c' situated at $20 \mathrm{~km}$. Biomass and chlorophyll pigments showed a significant and positive relationship with the distance from the source.
\end{abstract}

Key words: Air pollution, Brassica juncea, biomass, chlorophyll.

\section{INTRODUCTION}

Air pollution and particulate matters emitted as smoke from a thermal power plant causes environmental stress from the nearby vegetation and normally inhibiting the normal growth of the plants (Nighat et al. 1999, Singh et al. 2000 and Gupta and Iqbal 2005). These effluents of the power plants emitted from elevated chimneys into the atmosphere from a plume, ultimately reaches the ground at various distances and direction depending on the wind. The particulates and gaseous pollutants can cause synergistic or additive effects on the overall growth performance of the plants (Agarwal et al. 1982, 1983, Singh and Rao 1982, Kumar 1986, Khan and Usmani 1988).
The present report describes the effect of coal smoke pollution on the biomass and chlorophyll contents of winter crops of Brassica juncea variety Laha T 59 growing at various distance from the source of pollution.

\section{MATERIALS AND METHODS}

The thermal power plant complex of Kasimpur consists of three power stations and located along the irrigation canal about $16 \mathrm{~km}$ North- East of Aligarh $\left(27^{\circ} 58^{\prime} \mathrm{N}\right.$ and $28^{\circ} 3^{\prime} \mathrm{N}$ Latitude and $78^{\circ} 8^{\prime} \mathrm{E}$ and $78^{\circ} 93^{\prime} \mathrm{E}$ longitude, about $187 \mathrm{~m}$ above the sea level), India. The daily average of coal consumption in the whole complex during the winter season is about 145.11 MT low-grade sulphur rich bituminous type of coal per hour. The 
amount of the three major gases viz oxides of sulphur, nitrogen and carbon dioxide and particulate matters released from the power plant complex are shown in Fig. 1.

Five sites were selected at about 0.5, 2, 4, 6 and $20 \mathrm{~km}$ leeward from the above source of pollution, along the irrigation canal towards the south east direction where wind blow maximum in the year. The sites are identified as A, B, C, D and $\mathrm{E}$, respectively and fall in a track of soil which characterized by loam and clayey loam. The test plants were grown on these sites and irrigated and nourished with the basic dose of fertilizers (nitrogen, phosphorous and potassium) as recommended by Aligarh agricultural directorate. Site E (20 km away) was having apparently a negligible amount of air pollutants, served as reference site for comparison. Ten plants of 90 days old $B$. juncea were collected from each sites and compared their biomass (weighed after oven dried at $80^{\circ} \mathrm{C}$ ) and chlorophyll content (estimated according to Arnon 1949) with the reference site E. The data so obtained were analysed statistically. To obtain the relative degree of response of the biomass and chlorophyll pigments to coal smoke pollution, the per cent differences at sites 'A', 'B', ' $C$ ', 'D' compared with site ' $E$ ' (the reference site) were computed. The correlation coefficient and

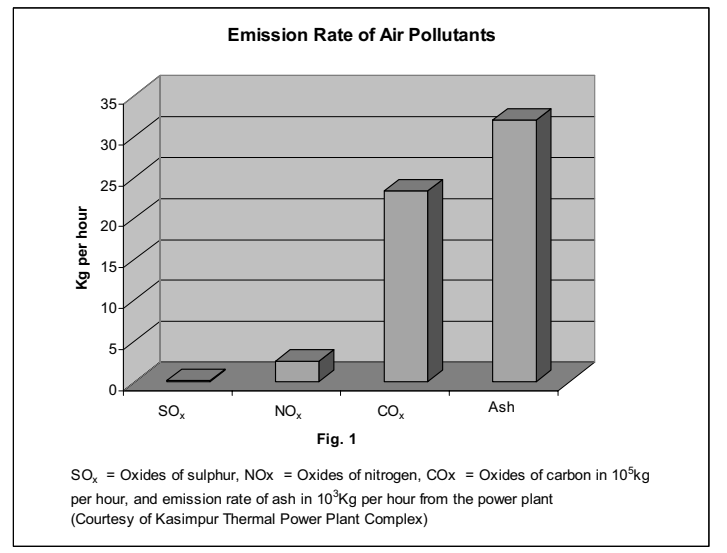

linear regression equation and per cent dependence of biomass and chlorophyll upon distance were also calculated (Table 1).

\section{RESULTS}

The data recorded from the present study indicates that the degree of loss in root, shoot and total biomass decreased with decreasing distance from the source of pollution. The percent loss in root biomass was found to be statistically significant up to $6 \mathrm{~km}$ while shoot and total biomass were significant up to $4 \mathrm{~km}$ in comparison to reference site situated at $20 \mathrm{~km}$ far from the source of pollution. But the severity of loss in all the cases were more prominent at site ' $A$ ' $(0.5 \mathrm{~km}$ far) than site ' $B$ ', ' $C$ ' and ' $D$ '. However the difference is not distinct in the statistical sense between site 'A', 'B' and ' $C$ '. Root biomass suffered greater loss $(86 \%)$ than shoot biomass $(83 \%)$ and total biomass $(83 \%)$ in comparison to reference site ' $E$ ' (Figs. 2, 3 and 4). The percent loss in Chlorophyll a, Chlorophyll b and total chlorophyll (Figs. 5, 6 and 7) followed the same trend as in case of shoot and total biomass of the plant. On Site 'A' chlorophyll a showed greater (30\%) but marginal loss than chlorophyll b (27\%) and total chlorophyll (28\%) in comparison to reference site 'E' (Fig. 5, 6 and 7).

The percent dependence of biomass and chlorophyll pigments upon distance from the power plant, the correlation coefficient, linear regression equation are all shown in Table 1 . The root biomass showed a relatively greater degree of dependence $(62 \%)$ on distance than shoot biomass $(57 \%)$, total biomass $(60 \%)$, Chlorophyll a $(52 \%)$, Chlorophyll b (45\%) and total chlorophyll (50). However, the total Chlorophyll showed 70\% dependence with total biomass of the plant. 


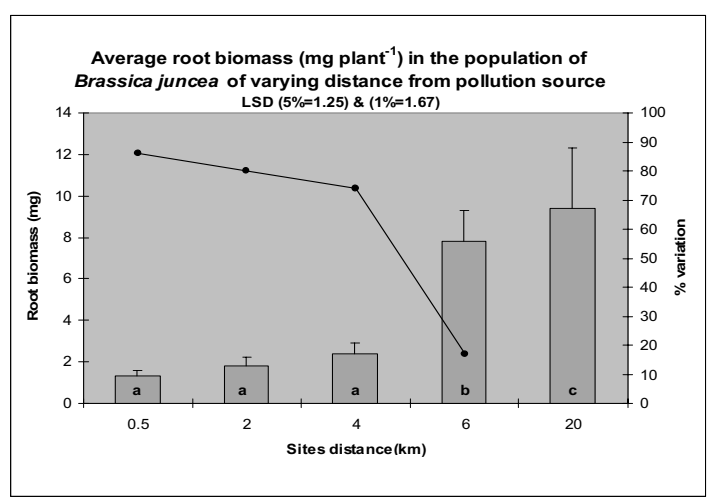

Fig. 2

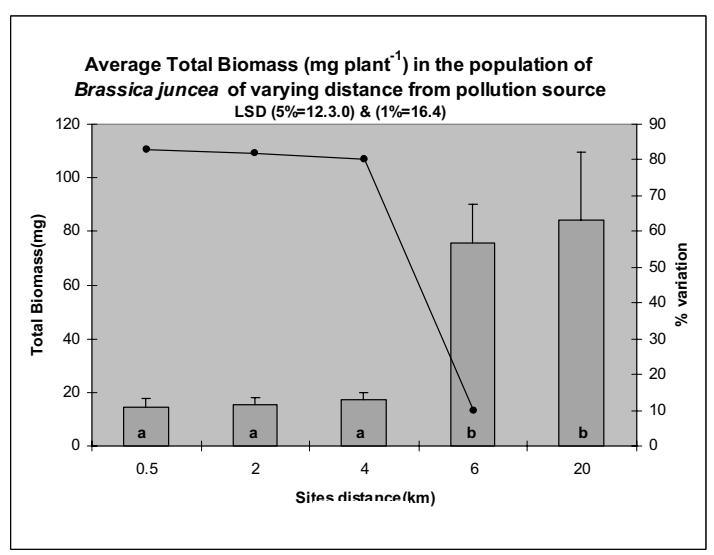

Fig. 4

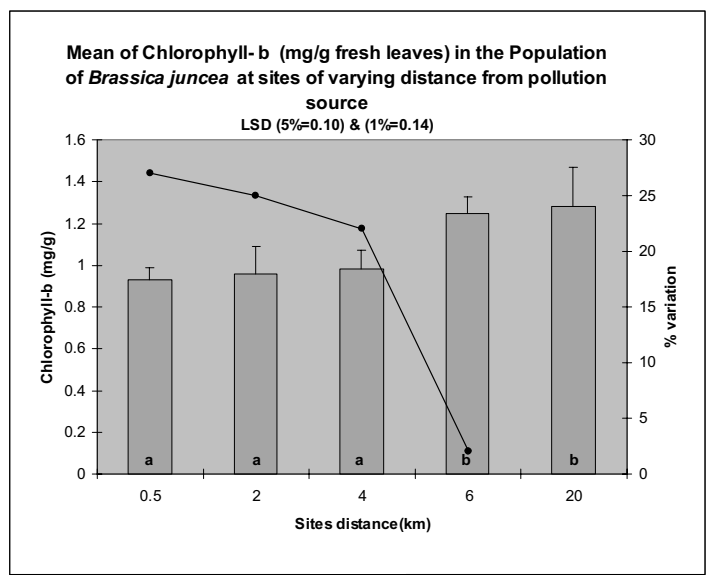

Fig. 6

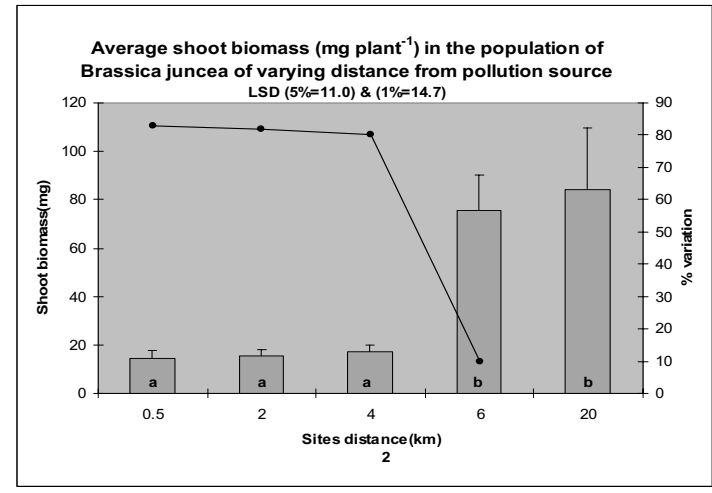

Fig. 3

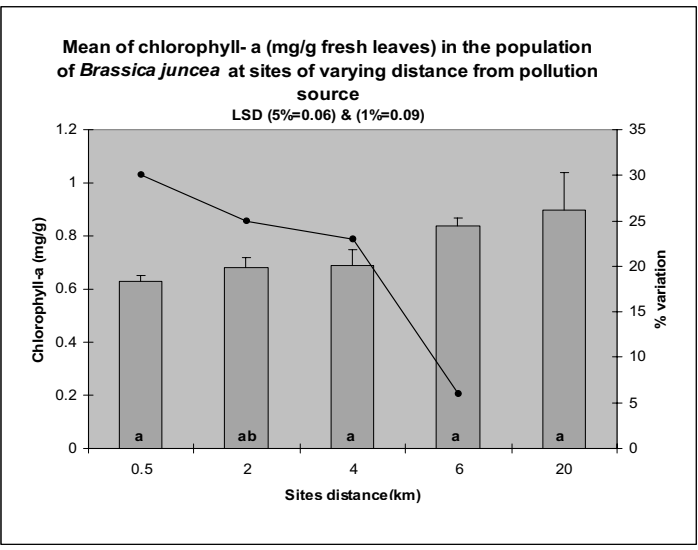

Fig. 5

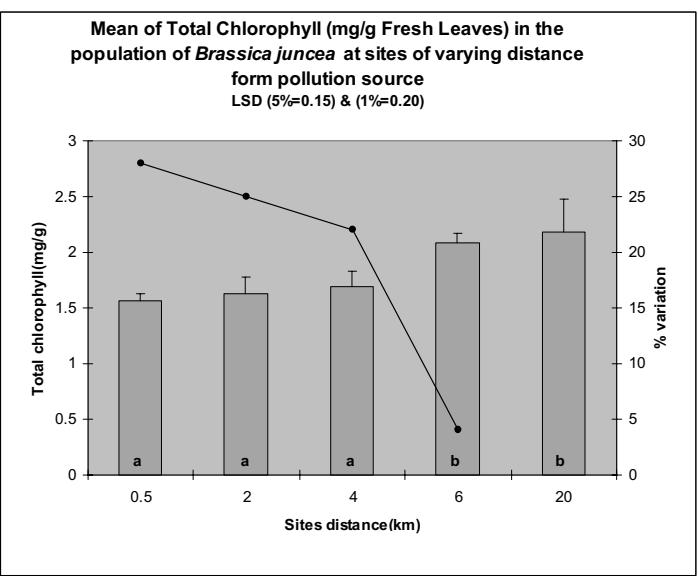

Fig. 7

\pm Standard deviation

LSD: Least significant difference at $5 \%$ and $1 \%$ level. Figures with the same suffix are not significantly different $(\mathrm{p}>0.05)$ from each other. Above data have been reduced to one decimal place after final calculation. 
Table 1. Correlation coefficient (r), percent dependence (\%) and linear regression equation $(\hat{\mathbf{Y}})$ of biomass and chlorophyll pigments upon the distance and between the total chlorophyll pigments and total biomass.

\begin{tabular}{lccc}
\hline Parameters & $\begin{array}{c}\text { Correlation } \\
\text { Coefficient }(\mathbf{r})\end{array}$ & $\begin{array}{c}\text { Percent Dependence } \\
(\mathbf{\%})\end{array}$ & $\begin{array}{c}\text { Linear regression equation } \\
(\hat{\mathbf{Y}}=\mathbf{a}+\mathbf{b x})\end{array}$ \\
\hline Root Biomass and Distance & $0.79^{* *} \pm 8.90$ & 62 & $\hat{\mathrm{Y}}=01.86+0.41 \mathrm{x}$ \\
Shoot Biomass and Distance & $0.76^{* *} \pm 8.00$ & 57 & $\hat{\mathrm{Y}}=17.40+3.70 \mathrm{x}$ \\
Total Biomass and Distance & $0.77^{* *} \pm 5.50$ & 60 & $\hat{\mathrm{Y}}=19.20+4.10 \mathrm{x}$ \\
Chlorophyll a and Distance & $0.72^{* *} \pm 0.10$ & 52 & $\hat{\mathrm{Y}}=00.73+0.01 \mathrm{x}$ \\
Chlorophyll b and Distance & $0.67^{* *} \pm 0.11$ & 45 & $\hat{\mathrm{Y}}=00.97+0.02 \mathrm{x}$ \\
Total Chlorophyll and Distance & $0.71^{* *} \pm 0.08$ & 50 & $\hat{\mathrm{Y}}=01.63+0.03 \mathrm{x}$ \\
Total Chlorophyll and Total Biomass & $0.84^{* *} \pm 0.08$ & 70 & $\hat{\mathrm{Y}}=-143.06+103.29 \mathrm{x}$ \\
\hline
\end{tabular}

\section{DISCUSSION}

A marked reduction in chlorophyll pigments resulted a further reduction in the biomass of the plant were studied by a number of workers under the stress of air pollutants as in the present investigation. (Kumar 1986, Singh and Rao 1986, Malabari et al. 1991, Dhir et al. 2001 and Wali et al. 2004). The views differ on the mechanism of air pollution induced chlorophyll loss. According to Singh et al. (1990a) the total chlorophyll continues to decrease with increasing Sodium Meta bisulphate $\left(\mathrm{Na}_{2} \mathrm{~S}_{2} \mathrm{O}_{3}\right)$ concentration in tomato leaves. Chlorophyll a is thought to be degraded to phaeophytin under $\mathrm{SO}_{2}$ affect by replacing $\mathrm{Mg}^{+2}$ ions from chlorophyll molecules. In chlorophyll $\mathrm{b}$, $\mathrm{SO}_{2}$ removes the phytol group of the chlorophyll $b$ molecules (Rao and Le blanc 1966). It has been suggested that at $\mathrm{pH} 2.2-3.5$, free $\mathrm{H}^{+}$ions are generated in the cell from splitting of $\mathrm{HSO}_{3}$ into $\mathrm{SO}_{3}$ and $\mathrm{H}^{+}$, and displacing $\mathrm{Mg}^{++}$from the tetrapyrol ring of chlorophyll molecules to degrade them into Phaeophytin molecules (Swannapinunt and Kozlowski 1980, Shimazaki et al. 1980). This photosynthetically inactive brown pigment does not help in continuing the normal photosynthesis process and causes the observed decrease in total chlorophyll of the leaf sample which ultimately resulted in the reduction of the biomass of root and shoot of the plant. The present observation shows that the percent loss in biomass due to coal smoke pollution is almost three times higher than the chlorophyll pigments at the vicinity. Since chlorophyll pigments play an important role in photosynthesis, its sensitivity hampers the biomass production.

Earlier workers have suggested that chlorophyll $\mathrm{a}$ is more sensitive than chlorophyll $\mathrm{b}$ in a polluted atmosphere (Singh et al. 1985, Singh and Rao 1986, Wali et al. 2004). But present data revealed that percent reduction in chlorophyll a and $b$ is almost equivalent. This confirms the earlier observation on the alfalfa leaves (Singh and Rao 1980) and gladiolus (Singh et al. 1990b). In the present study a direct relationship exists between the loss of chlorophyll pigments and biomass with the distance, as noted by earlier workers (Lal and Ambasht 1981, Dubey and Pawar 1985, Khan and Ghouse 1988). 


\section{REFERENCES}

Agrawal, M., P.K. Nandi and D.N. Rao. 1982. Effect of Ozone and Sulphur dioxide pollutants separately and in mixture of chlorophyll and carotenoid pigments of Oryza sativa. Water, Air and Soil Pollution 18:449445.

Agrawal, M., P.K. Nandi, and D.N. Rao. 1983. Ozone and Sulphur dioxide effects on Panicum miliaceum plants. Bull. Torrey Bot. Club 110:435-441.

Arnon, D.I. 1949. Copper enzyme in isolated chloroplasts, Polyphenoloxidase in Beta vulgaris. Plant Physiol. 24:1-15.

Dubey, P.S. and K. Pawar. 1985. Air pollution and plant response center. In: Perspectives in Environmental Botany. Vol. 1. (eds.) Rao, D.N., K.J. Ahmad, M. Yunus and S.N. Singh. Print House, Lucknow, India, pp. 101-118.

Dhir B, Mahmooduzzafar, T.O. Sodium, and M. Iqbal. 2001. Stomatal and photosynthetic responses of Cichorium intybus leaves to sulphur dioxide treatment at different stages of plant development. J. Plant Biol. 44:97-102.

Gupta, M.C. and M. Iqbal. 2005. Ontogenetic histological changes in the wood of mango (Mangifera indica L. cv Deshi) exposed to coal-smoke pollution. Environ and Exp. Bot. 54:248-255.

Khan, F.A. and A.K.M. Ghouse. 1988. Root growth responses of Anagallis arsenic L., Primulaceae to air pollution. Environ. Pollut. 52:281-288.

Khan, F.A. and N.R. Usmani. 1988. Effect of Sulphur dioxide on chlorophyll in Mustard leaf. J. Ind. Bot. Soc. 67:205-208.

Kumar, N. 1986. Response of Vigna radiata to $\mathrm{SO}_{2}$ and $\mathrm{NO}_{2}$ pollution. Act. Bot. Indica 14:139-144.
Lal, B. and R.S. Ambasht. 1981. Fluoride accumulation in a deciduous forest tree species in the neighborhood of an aluminum factory. Indian J. Forestry 4:261-264.

Malabari, A.A., Z. Ahmad, M. Saquib. 1991. Effect of air pollution on Gnephalium pensylvanicum Willd- a cropland weed. Geobios 18:7-10.

Nighat, F., Mahmooduzzafar, M. Iqbal. 1999. Foliar responses of Peristrophe bicalyculata to coal smoke pollution. J. Plant Biol. 42:205212 .

Rao, D.N. and Le Blanc. 1966. Effect of sulphur dioxide pollution on the lichen algae, with special reference to chlorophyll. Bryologist 69:65-69.

Shimazaki, K.I., T. Sakaki, D. Kondo and K. Sugahara. 1980. Active $\mathrm{O}_{2}$ participation in chlorophyll destruction and lipid peroxidation in $\mathrm{SO}_{2}$ fumigated leaves of spinach. Plant Cell Physiol. 21:1193-1204.

Singh, N., A. Gayoor, W.Y. Soh and M. Iqbal. 2000. Growth responses and Hyoscyamine content of Datura innoxia under the influence of coal smoke pollution. J. Plant Biol. 43:6975 .

Singh, N. and D.N. Rao. 1980. Studies of the effects of sulphur dioxide on alfalfa plants especially under condition of natural precipitation. Indian J. Air Pollut. Contr. 3:18 .

Singh, N. and D.N. Rao. 1986. Influence of sulphur dioxide on the growth and productivity of Phaseolus aureus plants. Acta Bot. Indica pp. 230-235.

Singh, S.N., M. Yunus and N. Singh. 1990a. Effect of sodium metabisulphite on chlorophyll, 
protein and nitrate reductase activity of tomato. Sci. Total Environ. 81:269-274.

Singh, N., S.N. Singh, K. Srivastava, M. Yunus, K.J. Ahmad, S.C. Sharma and A.N. Sharma. 1990b. Relative sensitivity and tolerance of some gladiolus cultivars to sulphur dioxide. Ann. Bot. 65:41-44.

Singh, S.N, M. Yunus, K. Srivastava, K. Kulshreshtha and K.J. Ahmad. 1985. Response of Calendula officinalis $\mathrm{L}$ to long-term fumigation with $\mathrm{SO}_{2}$. Env. Pollut. 39:17-25.
Swannapinunt, W. and T.T. Kozlowski. 1980. Effect of sulphur dioxide on transpiration, chlorophyll content, growth and injury in young seedlings of woody angiosperms. Can. J. For. Res. 10:178-181.

Wali, B., Mahmooduzzafar, M. Iqbal. 2004. Plant growth, stomatal response, pigments and photosynthesis of Althea officinalis as affected by $\mathrm{SO}_{2}$ stress. Ind. J. Plant Physiol. 9:224233. 